International Journal of Agriculture, Environment and Bioresearch

Vol. 4, No. 05; 2019

ISSN: $2456-8643$

\title{
STATE OF THE SCENE OF SLASH-AND-BURN ITINERANT AGRICULTURE IN THE MAYOMBE FOREST IN THE DEMOCRATIC REPUBLIC OF CONGO
}

\author{
Ngoma Nlandu Jacques ${ }^{1 *}$, Tasi Mbuangi Jean-Paul ${ }^{2}$, Mananga Mananga Placide ${ }^{1}$, Matwo Luke Steve ${ }^{3}$ \\ ${ }^{1}$ Faculty of Agricultural Sciences, University President Joseph Kasa-Vubu (UKV Boma), Po Box. 314 Boma, Kongo \\ Central, D R Congo \\ ${ }^{2}$ Faculty of Agricultural Sciences, University of Kinshasa, Department of Natural Resources Management, Po Box \\ 117 Kinshasa XI, DR Congo. \\ ${ }^{3}$ Faculty of Agricultural Sciences, University of Kikwit, Po Box 76 Kikwit, Kwilu, DR Congo.
}

http://doi.org/10.35410/IJAEB.2019.4435

\begin{abstract}
The Mayombe forest, precisely the forest of Mbavu region in the territory of Seke-Banza, is completely denuded due to slash-and-burn itinerant agriculture. This can lead to serious consequences such as changes in local climate, erosion of biodiversity, loss of soil fertility, decreased evapotranspiration resulting in scarcity of rains, runoff and drying up of Sources. The aim of this work is to make the state of the scene of slash-and-burn itinerant agriculture in the Mayombe forest, in the Mbavu sector of Seke-Banza territory. Its specific objectives are to describe the main activities of the population, to get an idea of the practice of clearing and logging by the population, to know the extent deforested by the population, the procedure followed by the population before planting, the crops used by the population for planting, the groups involved in this practice, as well as the quantity and duration of crops harvest by the population. The methodology of the work consists of randomly investigating, throughout the Mbavu sector, 60 peasants for 14 days to get information on itinerant slash-and-burn agriculture. The results show that the majority of farmers in the Mbavu sector practice agriculture and the rest of the population engages in education and other activities. The entire population clears, fells and incinerates trees to cultivate. Most farmers clear only one hectare of forest. Agricultural products grown are rice, maize and others, which range in quantity from 1 to 3 tons and are usually harvested after six months. The Makaba, Ngimbi and Nsundi groups are the most affected in the operation.
\end{abstract}

Keywords: slash-and-burn itinerant agriculture, Mayombe forest, socio-economic activities in the Mayombe region.

\section{INTRODUCTION}

After Brazil, the forests of the Democratic Republic of Congo (DRC) are the second largest mass of dense and humid tropical forests in the world. They are estimated at 155.5 million hectares representing nearly half of Africa's rainforest [1]. 
These forests are constantly being sought after by people in search of firewood, service wood and fertile land due to demographic pressure. In fact, nearly 30 million people, including more than 150 ethnic groups, currently live in the forests of Central Africa [2].

Like other tropical countries, crop clearing is the main cause of deforestation in Congo. Findings indicate that nearly 4 million people are producing food by clearing more than 400.000 hectares of forest each year [3].

In the « Kongo central » province in DR Congo, it was noted that the District of « Bas-Fleuve », precisely the territory of Seke-banza to which the Mbavu sectorbelongs, is completely denuded as a result of itinerant slash-and-burn agriculture. This can lead to serious consequences such as changes in local climate, erosion of biodiversity, loss of soil fertility, decreased evapotranspiration resulting in scarcity of rains, runoff and drying up of Sources.

Making a state of the area of itinerant slash-and-burn agriculture in the Mayombe forest in this environment is one of the fundamental elements to maintain ecological balance while increasing crop yields. Unfortunately, there are few studies that have been done on this subject. It is within this framework that the choice of this study is made.

The overall objective of this work is to makethe state of the scene of slash-and-burn itinerant agriculture on the Mayombe forest, which is located in the Mbavu sector of Seke-Banza territory. Its specific objectives are to describe the main activities of the population, to get an idea of the practice of clearing and logging by the population, to know the extent deforested by the population, the procedure followed by the population before planting, the crops used by the population for planting, the groups involved in this practice, the quantity and the duration of crop harvest by the population.

\section{MATERIAL AND METHODS}

\section{Study environment}

The sector of Mbavu where our study was conducted is located on the Seke-Banza-Sumbi and Tshela-Sumbi highway in Seke-Banza territory, district of «Bas-Fleuve », province of « Kingo central » in the Democratic Republic of Congo. The Mbavu sector has an area of $512 \mathrm{~km} 2$, or $14.14 \%$ of the territory of Seke-Banza and has 34927 inhabitants [4]. It has 9 groups including Matamba, Khuni, Makaba, Mbenza, Sanzulu, Kavuzi, Nziuti, Nsundi, and Phudi.

\section{Methodological approach}

In order to conduct this study, a survey was conducted in the Mbavu sector for 14 days, from April 06, 2019 to April 20, 2019 using a survey questionnaire. We randomly selected 60 resource people across the sector to have a fairly representative sample. We then took images through a digital camera with the aim of bringing out the steps of slash-and-burn agriculture in our study area.

The parameters studied are the following (i) main activities of the population, (ii) practice of land clearing and logging by the population; (iii) extent deforested by the population; (iv) procedure followed by the population before planting; (v) crop used by the population for planting; (vi) 
duration of crops harvest ; (vii) groups involved in this practice; (viii) and the amount of crop harvested by the population.

\section{Statistical analysis of data}

The information on the parameters studied was analyzed using Excel software to express them in proportions.

\section{RESULTS AND DISCUSSION}

\section{Slash-and-burn itinerant farming steps in the Mbavu area}

Figures 1, 2, 3 and 4 below illustrate the different steps of slash-and-burn itinerant agriculture in the Mbavu sector. In this area, the population begins by burning the forest after clearing it to obtain land ready to be cultivated. After that, the population cultivates the land for 2 or 3 years. After a fallow of more than 15 years, there is regeneration of a secondary forest. The farmer practising, in fact, the slash-and-burn culture realizes that the fertility of the soil is linked to the state of the forest; This is confirmed by soil research that establishes the relationship between nutrients and biomass in the rainforest ecosystem; better biomass is developed, better nutrients are available for crops. Minimum 15 to 20 years of fallow allow some regeneration of the forest with less impact on yield and also biodiversity. After two or three cycles of exploitation, the degradation of soil fertility forces the farmer to move his crops. The land is left fallow and a new plot is deforested by burns. This confirms the results obtained by [5] through a similar study.

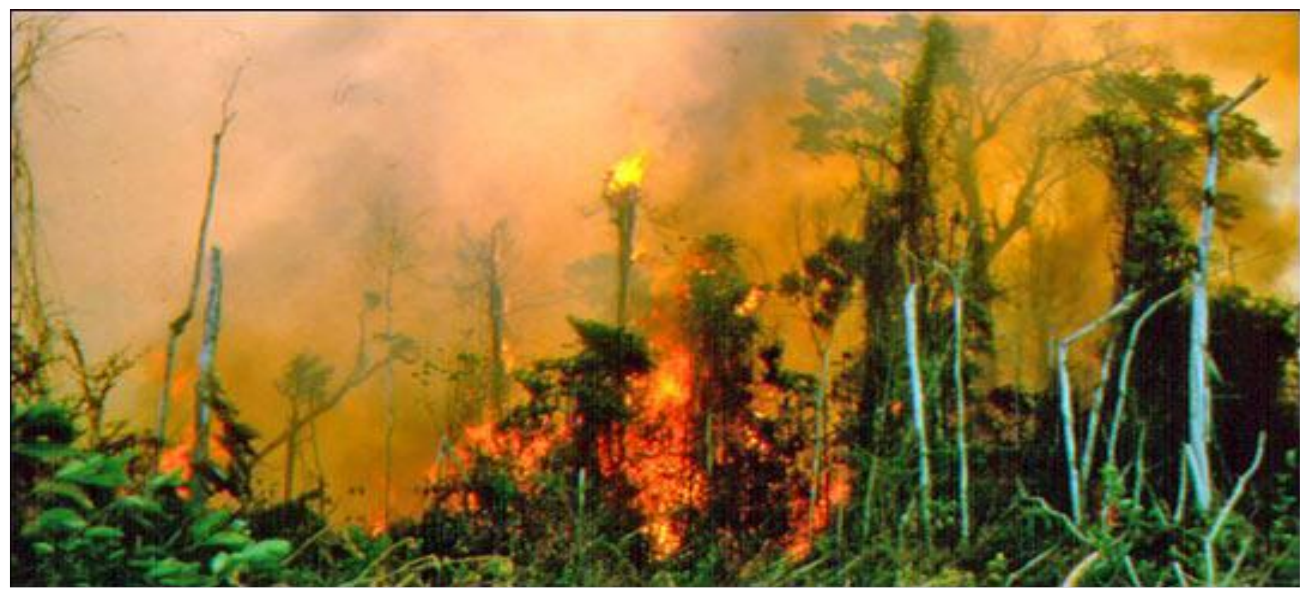

Figure 1. Burning of the forest after clearing in the Mbavu sector in Mayombe 


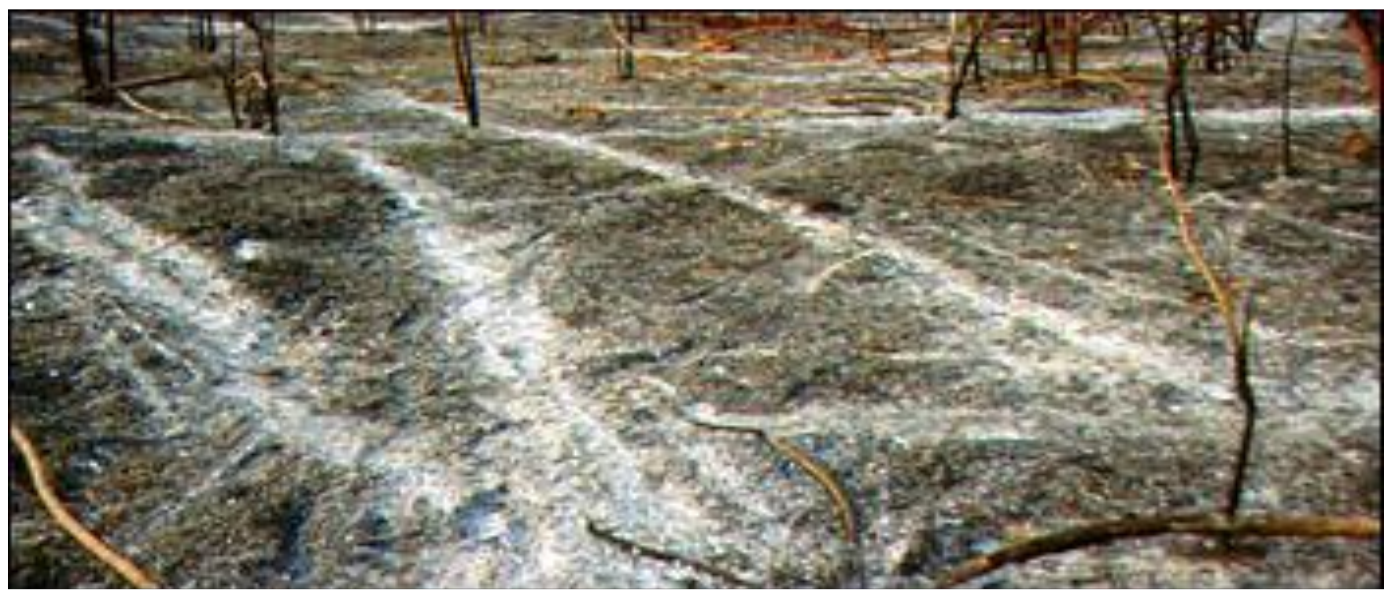

Figure 2. Land ready to be cultivated in the Mbavu sector in Mayombe

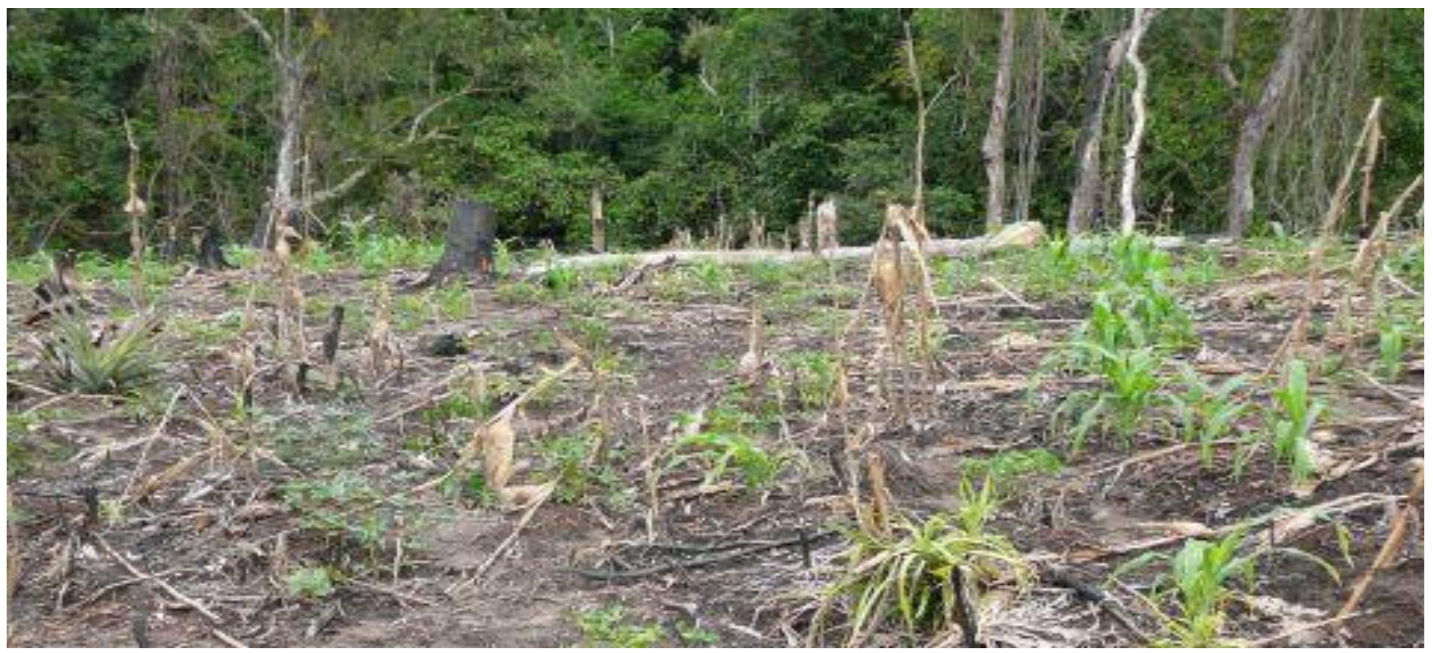

Figure 3. Land culture for 2 or 3 years in the Mbavu sector in Mayombe

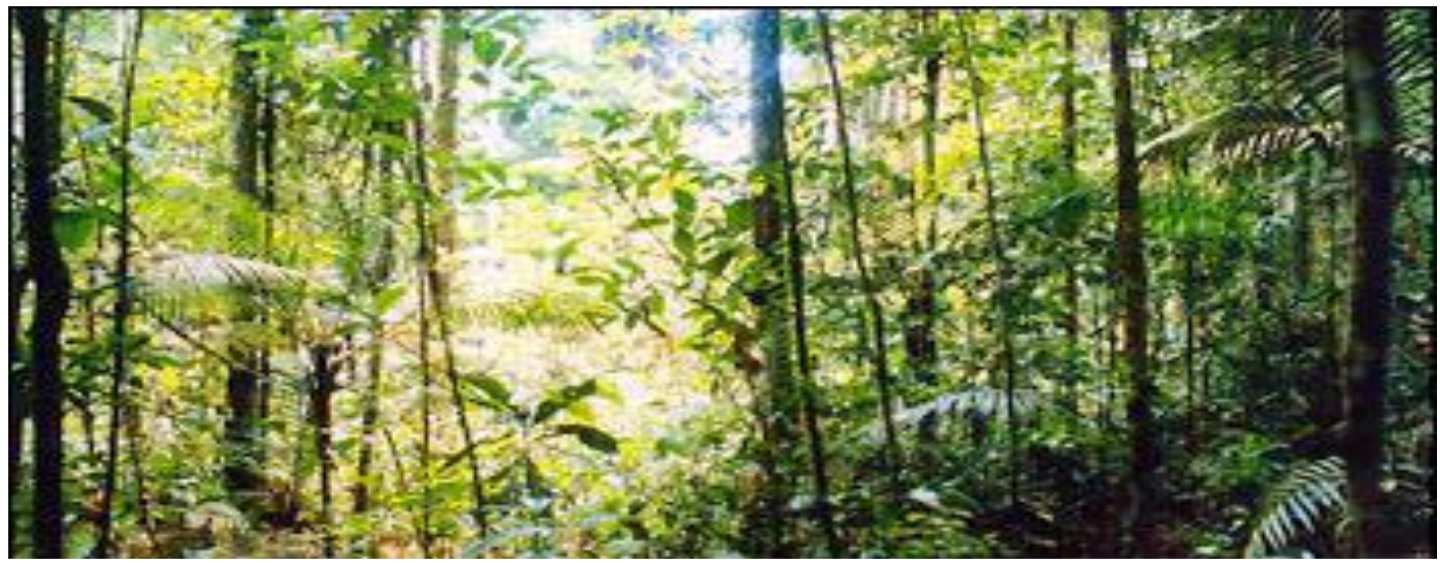

Figure 4: Regeneration of a secondary forest after fallow period - 15 years in the Mbavu sector of Mayombe 


\section{Main activities of the population}

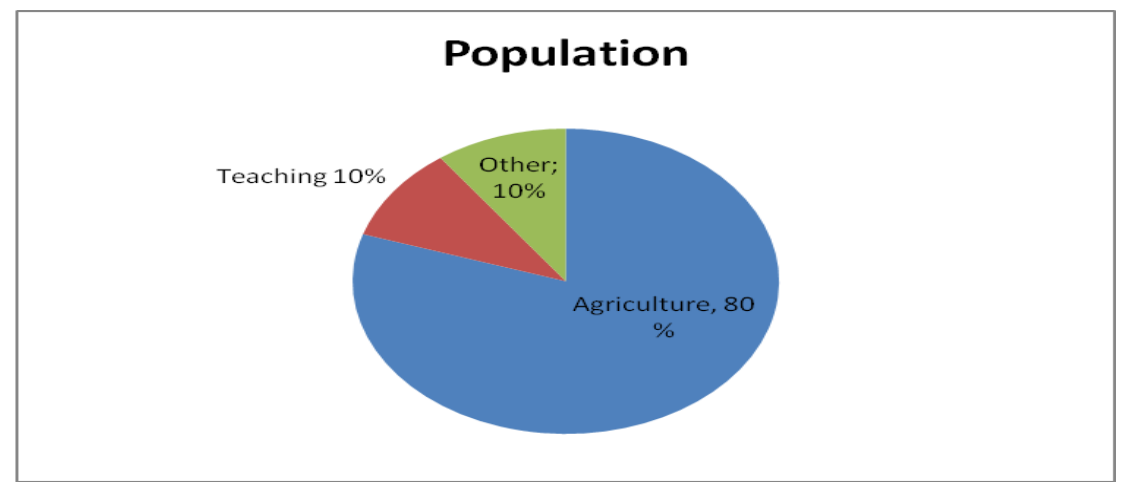

Figure 5: Main activities of the population

Figure 5 below shows the main activities of the population of the Mbavu sector. It follows from this figure that $80 \%$ of the population of the Mbavu sector practices agriculture, $10 \%$ of the population are teachers and $10 \%$ do other activities. This situation is due to the fact that agriculture is an empirical activity. These results are similar to those found by [5] and [6] through similar studies.

\section{Practice of land clearing and logging by the population}

In the Mbavu sector, the entire population clears and downs trees to cultivate. This is because fertility is linked to the tree and the population ensures its food production by clearing the forest every year. This confirms the results of [5], [6], and [7].

\section{Forest area deforested by the population}

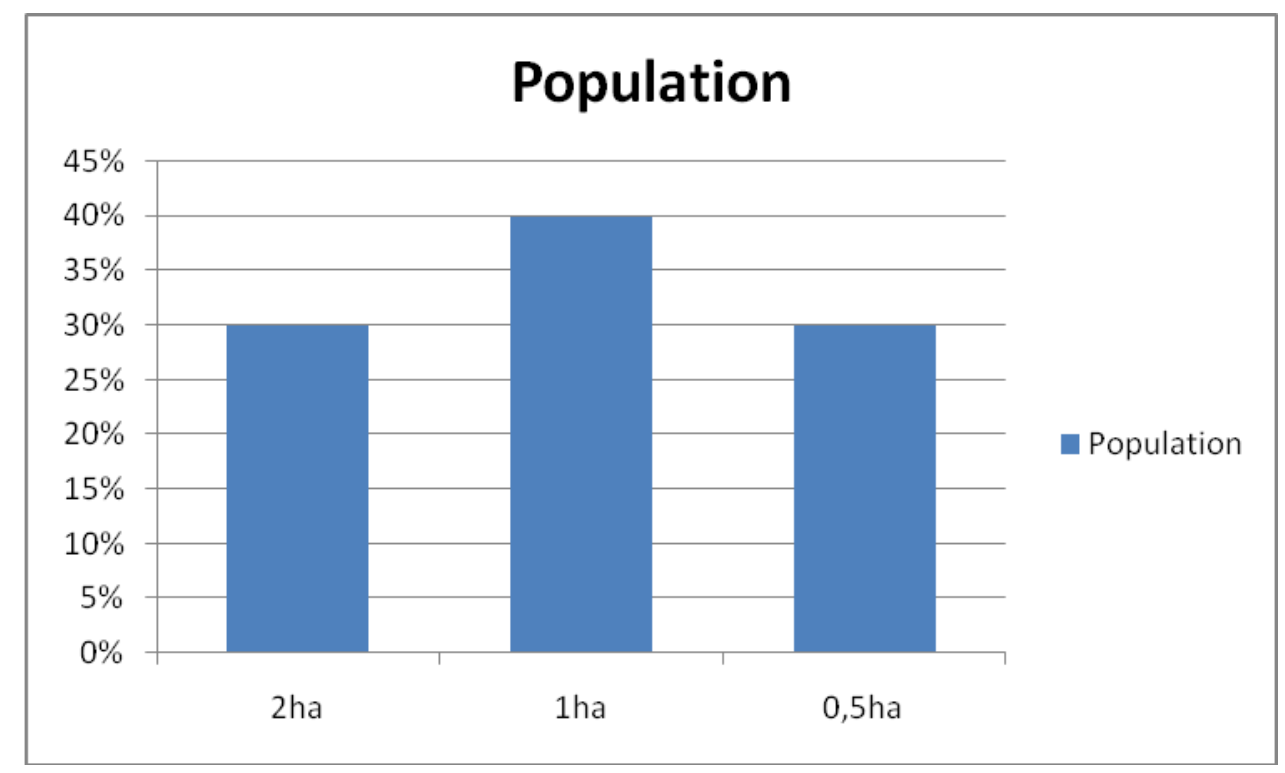


Figure 6. Forest area deforested by the population

Figure 6 illustrates the forest area deforested by the population. As a result, $40 \%$ of the population clears 1 ha of forest for agriculture, $30 \%$ of the population clears 2 hectares of forest and $30 \%$ of the population clears 0.5 hectares of forest for agriculture. This is because the population has become accustomed to clearing these areas. Large areas are uncontrolled and their clearing is tedious, sometimes expensive. These results do not contradict those obtained by [5], [6], and [7] through similar studies.

\section{How the population is followed before planting}

In the Mbavu sector, the entire population practices incineration before the cultivation of crops. This behaviour is empirical and allows crops to develop well.

\section{Cultures used by the people of the Mbavu sector for planting}

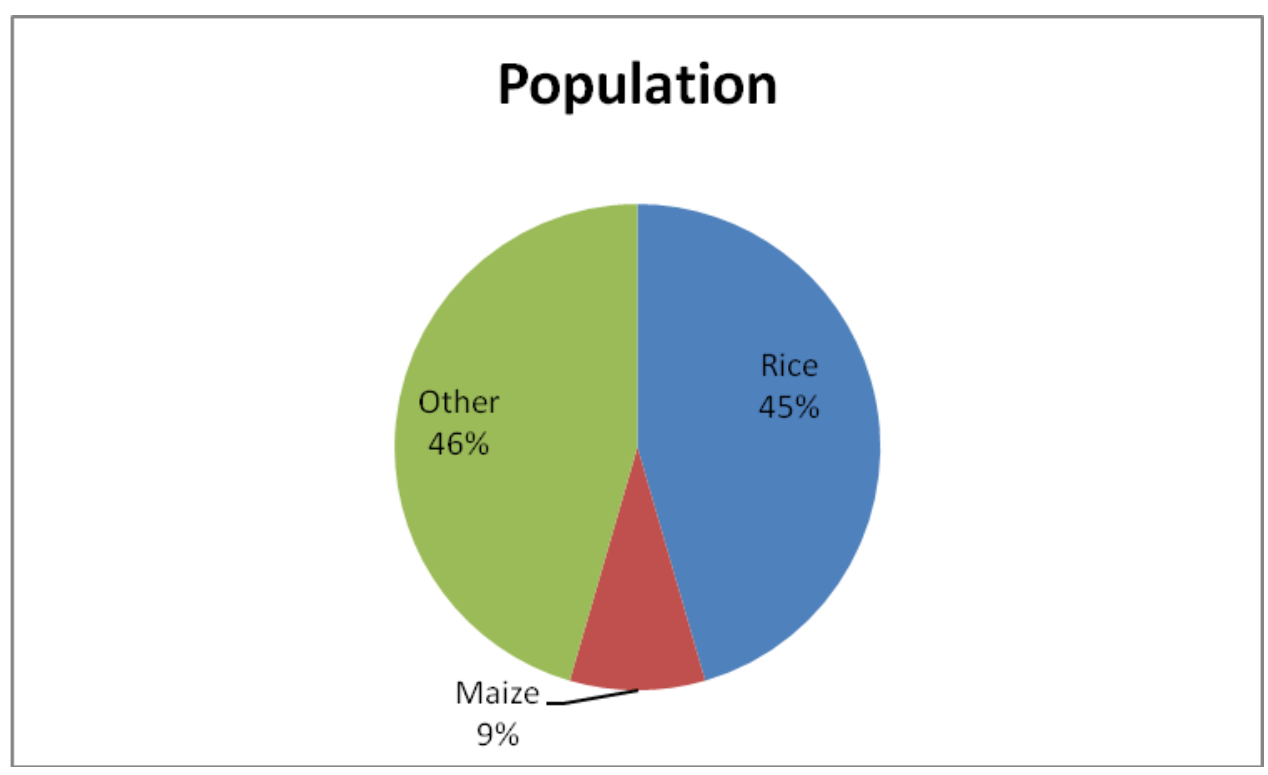

Figure 7: Cultures used by the population for planting

The crops used by the population are recorded in Figure 7. This figure shows that $45.5 \%$ of the population is rice growing, $9 \%$ of the population is maize growing and $45.5 \%$ of the population grow other plants. This situation is justified by the fact that rice is the most popular commodity for the population of the Mbavu sector. 9\% of the population grow maize because it is not preferred by the population and $45.5 \%$ of the population grow other agricultural products such as yams because they are preferred to the same feet of equality as rice. This contradicts to a lesser extent the studies conducted by [8] and [9] respectively in the Nsumbi and Bundi sectors which revealed that yams were more cultivated.

Duration harvest crops

Table 1: Crop harvest duration 


\begin{tabular}{|cc|}
\hline Harvest duration & Population \\
\hline 6 months & $80 \%$ \\
4 months & $12 \%$ \\
3 months & $5 \%$ \\
Other & $3 \%$ \\
\hline
\end{tabular}

The results for crop duration are recorded in Table 1 . This table shows that $80 \%$ of the population wait 6 months to harvest crops and $12 \%$ of the population wait 4 months, $5 \%$ of the population wait 3 months and 3\% of the population wait for other durations. This depends on one crop to another and confirms studies of [8] and [9] on the duration of crops in the Nsumbi and Bundi sectors.

\section{Groups involved in this practice}

Table 2. Groups involved in this practice

\begin{tabular}{|cc|}
\hline Groups & Population \\
\hline Mbenza & $30 \%$ \\
Makaba & $20 \%$ \\
Nsundi & $10 \%$ \\
Ngimbi & $20 \%$ \\
Other & $20 \%$ \\
\hline
\end{tabular}

The groups involved in the practice of itinerant slash-and-burn agriculture in the Mbavu sector are illustrated in Table 2. This shows that $30 \%$ of this population are from the Mbenza grouping, $20 \%$ of the population are from the Makaba grouping, $20 \%$ of the population are from the Ngimbi grouping, $10 \%$ of the population are from the Nsundi grouping and, $20 \%$ of the population are from other groups.

Quantity of agricultural products harvested by the population

Table 3. Quantity of agricultural products harvested by the population

\begin{tabular}{|cc|}
\hline Quantity in ton & Population \\
\hline 1 ton & $30 \%$
\end{tabular}




$\begin{array}{lc}2 \text { tons } & 40 \% \\ 3 \text { tons } & 20 \% \\ 0.5 \text { ton } & 6 \% \\ \text { Other } & 4 \%\end{array}$

Table 3 shows the quantity of crops harvested by the population. This table shows that $40 \%$ of the population harvest 2 tons of agricultural products, 30\% of the population harvest 1 ton, $20 \%$ of the population harvest 3 tons and, $6 \%$ of the population harvest 0.5 tons and $4 \%$ harvest other quantities of the agricultural products. This is due to soil fertility and confirms studies of [8] and [9] on the quantity of agricultural products harvested in the Nsumbi and Bundi sectors.

\section{CONCLUSION}

The overall objective of this work was to take stock of slash-and-burn itinerant agriculture in the Mayombe forest in the Mbavu sector of Seke-Banza territory.

The work consisted of conducting a survey in the Mbavu sector for 14 days to get an idea of the main activities of the population, the practice of clearing and logging by the population, the extent deforested by the population, procedure followed by the population before planting, crop used by the population for planting, the duration to harvest crops, the groups involved in this practice as well as the quantity of agricultural products harvested by the population. We randomly selected 60 resource people across the sector to have a fairly representative sample.

The results found showed that the majority of the population of the Sector Mbavu practices agriculture. The whole population clears and downs trees to cultivate. The population often clears an area of forest of 1 to 2 hectares for agriculture. The whole population practices incineration before the cultivation of crops. Rice farming and the cultivation of other agricultural products such as yams are much more practiced and maize is grown to a lesser extent. Most of those involved in slash-and-burn itinerant agriculture in the Mbavu sector, coming from the Mbenza, makaba, Ngimbi and Nsundi groups, harvest between 1 and 3 tonnes of agricultural products after a period of 3 to 6 months.

Ultimately, this population in the Mbavu sector must look for techniques that should allow both to produce sufficient food and to maintain or, if necessary, to restore soil fertility. Thus for better land use, the agroforestry approach is relevant; (ii) that the state disseminate agroforestry to the peasant masses to combat environmental degradation in the Mbavu sector; (iii) that farmers enrich degraded forests so that they can be restored; (iv) that the state set up ecological guards for surveillance in order to compensate for crop clearing; and (v) the state enforces the forest law and its enforcement measures to farmers to take ownership of it in order to sustainably manage the forest resources of the Mbavu sector.

\section{ACKNOWLEDGMENTS}


Our thanks go to the faculties of Agricultural Sciences from Universities of Kasa-Vubu (Boma), Kinshasa and Kikwit for their proven contributions to this research.

\section{REFERENCES}

[1] Congo Basin Forest State 2008. Congo Basin Forest Partnership (PFBC), Brazzaville. 115pp.

[2] Annual Report of socio-economic activities in the city of Boma: Boma Urban Housing and Energy Office, Bas-Congo Province, DRC.

[3] Kadiata, B. 2005. General Forestry: course notes, Faculty of Agricultural Sciences, University of Kinshasa, DR Congo.

[4] Archives of the Mbavu sector on the enrolment 2011: Archives of the Mbavu sector, Independent National Electoral Commission, DR Congo.

[5] Nsenga, L. 2012. Introduction to slash-and-burn itinerant agriculture: Seminar, Program Manager, Bas-Congo, WWF-RDC.

[6] Seke, M. 2013. Impact of slash-and-burn itinerant agriculture on the Mayimbe forest: cases of the Nsumbi and Bundi sectors: final dissertation. Department of Natural Resources Management, Faculty of Agricultural Sciences, Kasa-Vubu University.

[7] Mabuidi, K. 2018 Problem of deforestation of the Mayo Forest forests of the Bundi, Mbavu and Nsumbi areas: final disseratation. Department of Natural Resources Management, Faculty of Agricultural Sciences, University of Kinshasa.

[8] Kuisi, M. 2015. Impact of Anthropogenic Activities on the Mayombe Forest: Final Memory. Department of Natural Resources Management, Faculty of Agricultural Sciences, University of Kasa-Vubu, DR Congo.

[9] Tasi, M. 2018. Bibliographic summary on deforestation in the Mayombe area: Seminar. Department of Natural Resources Management, Faculty of Agricultural Sciences, University of Kasa-Vubu, DR Congo. 